\title{
CONTRIBUTION TO THE STUDY OF HEART DISEASE IN THE HORSE.
}

By Stewart Stockman, M.R.C.V.S., Demonstrator of Pathology, Dick College, Edinburgh.

CAUSATION.

THE amount of literature, in the English language, on the cardiac affections in the horse might lead one to suppose that heart disease in that animal is infrequent enough to render it of secondary importance. According to most writers valvular lesions result from chronic inflammation of the endocardium. It is true that rheumatism, so frequently the starting-point of endocarditis in human beings, is much less common in the adult horse, but in the latter endocarditis may arise in the course of some of the infectious diseases, such as influenza. I have in my possession the hearts of horses dead of acute endocarditis, which came on during an attack of influenza. In some districts endocarditis is frequently met with in foals as the result of rheumatism, but these animals seldom reach maturity. Some authors accuse cold and violent exertion. I fail to see how the former of these causes could account for endocarditis, but I have reason to believe that a valve may undergo thickening and contraction as the result of a rupture produced by a violent effort. Trasbot writes that "one of the principal causes of chronic endocarditis in the horse is work which necessitates an over activity of the heart." Dilatation of the right heart without anatomical changes in the valves may be produced by long continued over exertion, as I shall try to show when dealing with tricuspid incompetence. In the $\operatorname{dog}$ I have met with a case of dilation of the left ventricle without hypertrophy, which could only be accounted for by the fact that the animal had advanced cirrhosis of the liver.

ANATOMICAL CHANGES.

As the result of chronic endocarditis vegetations appear on the valves. The cusps become thickened and contracted to such an extent that they can no longer fulfil their physiological function. They become incompetent, allowing the blood to pass backwards. The consequent increase of pressure in the chamber posterior to the incompetent valve brings about a permanent dilatation thereof. In this way a valve may become incompetent without its cusps having undergone any anatomical alterations. For instance, if the aortic valve be incompetent, the blood will pass backwards into the left ventricle during its diastole, augmenting the outward pressure exerted on its wall by the flow from the auricle. The chamber, unable to contain this abnormally large supply of blood, becomes dilated, may be to such an extent as to render the mitral valve incapable of closing the auriculo-ventricular orifice at the commencement of systole, but, as the contraction proceeds, it seems to become competent again. Probably, when the ventricle is much dilated, the cordæ tendineæ prevent the cusps from overlapping at the start of systole.

Usually, however, these secondary changes are limited by a compensatory hypertrophy of the musculąr wall, so that the organ becomes absolutely enlarged. Chronic endocarditis may also result 
in narrowing of the orifices from the formation of new tissue at the base of the cusps. When an orifice is constricted an obstacle is offered to the passage of blood through it, and to overcome this the posterior chambers become hypertrophied. The valves may also become incompetent as the result of calcification, which may take place with or without chronic endocarditis. Calcification of the aortic semilunar valves may also follow atheroma of the aorta. I have met with one such case. My records of post-mortem examinations are too few to allow me to draw up statistics of the relative frequency of lesions at the different orifices. The following statistics are given by Friedberger and Fröhner. Out of fifteen observations the left heart was found affected in seven, the right side in three, and in five the lesions were found on both sides. Out of forty-two cases observed by Nocard, thirty-eight presented lesions of the aortic valves alone. The remaining four showed lesions of the aortic and mitral valves.

In fourteen cases observed by Cadiot and Ries, ten presented lesions of the semilunars alone. The mitral was alone affected in one case, and two showed lesions of the aortic and mitral. (Pathol. et Therapeut. des Animaux domestiques. Fr. Trans. by Cadiot and Ries.)

These authorities seem to have confined their observations to cases showing distinct anatomical lesions. I feel sure, however, that simple dilatation of the right ventricle, causing slight tricuspid incompetence, is by far the most common affection of the heart in the horse.

\section{GENERAL SYMPTOMS.}

The effect of valvular lesions is to raise the pressure in the venous system throughout the body. If the lesion be on the left side of the heart, the backward pressure is at first mainly exerted on the pulmonary capillaries; if on the right, stagnation occurs in the systemic veins. Most of the secondary symptoms, such as those of congestion of the portal branches in the liver and stomach, and cedema of the respiratory membrane, are called up by the existence of venous congestion. As long as the hypertrophy is compensatory and the animal is not over-worked, the general health is fairly good; but as soon as the heart becomes weakened from other disease, over-work, or old age, secondary circulatory troubles arise. I must mention, however, that I have met with a case of aortic incompetence in a thorough-bred horse, whose owner pronounced him capable of passing anything on the road.

When a heart-disease patient is brought for consultation, inquiry generally elicits the following history. The animal does not work well. He suffers from dyspnoea on the slightest exertion. He coughs frequently. The appetite is poor, digestion is disturbed, and the general condition is bad. The bursa and dependent parts are often swollen after standing in the stable over night. The Schneiderian mucous membrane is usually bluish in colour. The conjunctiva may be yellow. The pulse is often normal, but it may be intermittent or irregular. After trotting for a few minutes the respiratory movements and the pulse are greatly increased in frequency. They do not return to the normal for some considerable time.

Abnormal pulsations are seen in the jugular veins. In the more 
serious cases there is a history of fainting, but I think this is the exception. In the dog the venous congestion commonly enough gives rise to dropsy of the cavities, but in the horse ascites and hydrothorax secondary to a cardiac lesion are not frequent. If I am to judge by the number of cases in which I have found the urine albuminous, chronic venous congestion of the kidney must also be a rare secondary lesion in the horse. I have frequently examined the urine for albumen without result. On one occasion some urine was withdrawn from a heart-disease patient dying of hypostatic congestion of the lungs, but no albumen was found in it.

Veterinary literature on the heart contains a few cases of embolism in important organs-brain and lungs-arising from vegetations or clots carried from the heart. The cardiac impulse may appear abnormally well marked or the opposite.

Lastly, we have the presence of murmurs to guide us. Their identification will be the chief object of this paper.

\section{TREATMENT.}

A horse with valvular disease is certainly unsound, but he is not useless. The general idea seems to be that such an animal will almost certainly fall dead. This is a mistake. I venture to think that most of the cases of sudden death from heart affections are due to degeneration of the cardiac muscle or to the rupture of a diseased aorta. Aortic incompetence is the valvular lesion most likely to cause sudden death, but my observation on hremorrhage in such a case shows that liberties can be taken even with them. There can certainly be little danger in driving such an animal in a fourwheeled trap. In the majority of heart cases compensatory hypertrophy takes place and the animal will do useful work, if carefully handled. An animal with valvular disease should not be made to do hard or fast work. The use of digitalis in the treatment of heart disease is almost universal. It slows the heart by lengthening diastole, giving the ventricles time to fill and their muscular fibres time to nourish themselves. Under its influence the contraction of the heart is more forcible and the pressure rises. Trasbot has obtained good results by combining it with iodide of potassium. On theoretical grounds it would be contra-indicated to prolong the diastole in aortic insufficiency, seeing that regurgitation into the left ventricle goes on all the time, and it must not be forgotten that digitalis irritates the gastric mucous membrane. For the latter reason the drug should be given in small doses two or three times daily. Friedberger and Fröhner advise the administration of cafeine sodo-benzoate $(\overline{\mathrm{i}} \mathrm{i}-\mathrm{ii})$, when prolonged treatment is called for. They consider its diuretic action more powerful and its toxic effects less than those of digitalis. Usually the practitioner is called in by the owner to treat symptoms of dyspnoea and gastric derangement. Their treatment must not be neglected. One can relieve the venous congestion by giving a saline purge, and digestion can be stimulated by carminatives with digestible and nourishing food.

The carminatives also exercise a stimulating effect on the heart. Dropsy of the dependent parts should be treated by bandaging, gentle exercise, and diuretics. 
The following prescription I have found useful as a diuretic:-

\author{
Digitalis Pulv. ji. \\ Potassii Acetatis $\bar{\jmath} s s$. \\ Ol. Juniperi m.m xxx. \\ M. f. bol. \\ Sig. One ball at night.
}

THE CARDIAC IMPULSE.

In the horse, according to Colin, the impulse is given to the chest-wall by the heart being thrown to the left at the beginning of each systole.

The impulse is given by the lower third of the left ventricle and is best felt in the 5 th intercostal space. The apex itself causes no appreciable shock, for, as the same authority has pointed out, it is turned from the left side, instead of towards it as in man and most of the carnivora. Whatever the explanation of the impulse may be, it is true that in the horse it is given by a part of the ventricle some distance from the apex. One looks for it a few inches from the floor of the sternum. Most physiologists, however, seem agreed that the impulse depends on the hardening of the heart muscle previous to contraction. According to the now classical experiments of Chauveau and Marey, the expanding ventricle, as it approaches the chest-wall, raises it, particularly at the time of the auricular contraction. This is represented by the wave $a^{\prime}-b^{\prime}$ in their tracings. It is immediately followed by a larger and longer maintained wave $c^{\prime}$, which again is succeeded by a fall, as the contracting ventricle recedes from the chestwall. In all the cardiograms that I have obtained from the horse these two waves are represented. (Fig. $8 \mathrm{~A}$.)

The cardiograph is of little use for purposes of diagnosis, as most of the results obtained by it can be got at by simpler and more reliable methods. Where the left ventricle is much hypertrophied, the ventricular wave is much longer maintained. This is shown in Fig. $8 \mathrm{~B}$, which I took from a horse with aortic incompetence. By means of the cardiograph intermittences of the heart may be graphically recorded. Figure $\& C$ is a cardiogram taken from a horse, which after excitement showed intermittency of one revolution following every five beats. The latter cardiogram was taken by means of a cup closed by a membrane and filled with spirit. Fluid waves were transmitted at each impulse to a spring kymograph. The shock is not so well represented as in the others, which were taken by a Knoll's cardiograph.

\title{
THE POSITION OF THE HEART OF THE HORSE IN RELATION TO AUSCULTATION AND PERCUSSION.
}

Before discussing the cardiac affections which come under the head of valvular lesions, I should like to point out the relation of the different parts of the heart to the chest-wall. I shall attempt to do so by means of figures made from photographs of dissections. I have taken all the photos. from subjects in the dissecting room of the Dick College, and in each case the heart was fully injected. I examined the heart of each animal before slaughter, and have only photographed those which exhibited no valvular lesion. The figures representing the normal areas have all been made from photos. of sound animals, 
those representing the unsound have been made from patients exhibiting the lesion in question.

The different areas will be spoken of in relation to the ribs and intercostal spaces. Accordingly, on each animal I have, as carefully as possible, marked out the position of each rib with chalk before making the photograph. In counting the ribs it is, of course, necessary to begin at the posterior one (18th) and proceed forwards. The areas of percussion and conduction of murmurs have been similarly marked with chalk after a careful examination of the animal. I have used a pleximeter and percussing hammer for percussion, and for auscultation a binaural stethescope. I find that a more accurate examination can be made by the aid of these instruments.

The heart of the horse is suspended by the large vessels from the middle line of the chest-roof. The base-auricles-extends a little more to the right of the middle line of the chest than to the

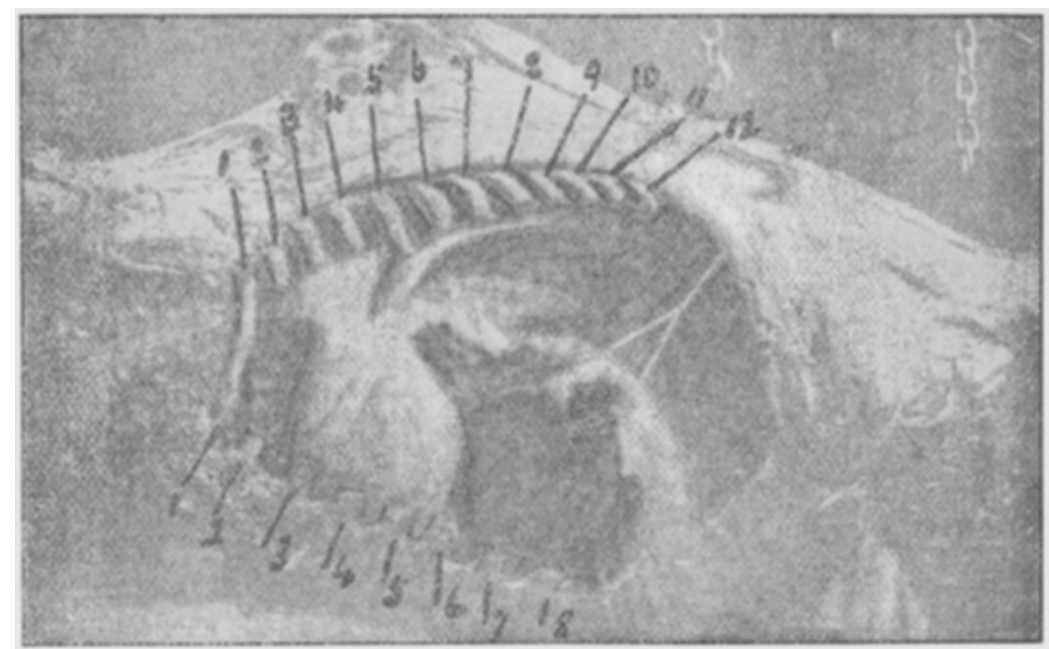

FIG. 1.

left, but, as the organ projects to the left as well as downwards and backwards, one of its most important parts-left ventricle-approaches the chest-wall on the left side. It approaches it near enough to influence the percussion note in certain areas.

The anterior portion of the left side of the heart with the exception of the apex is formed by part of the right ventricular wall. This portion of the right ventricle corresponds to the $3 \mathrm{rd}$ rib and space. (Figs. I and 2.) In this region the right ventricle and pulmonary artery bulge to the left. They lie some little distance from the chest-wall, being separated from it in the living animal by a thin layer of lung tissue. This is the only portion of the right ventricle which can furnish signs to percussion except under extraordinary conditions. The left ventricle begins at the 4 th rib and extends backwards into the 6 th intercostal space. (Figs. I and 2.) The apex lies on the floor of the chest and corresponds to the 6th costo-sternal cartilage. It is only the base of the left ventricle that extends beyond the 6 th rib. (Figs. I and 2.) About the 6 th 
rib the wall curves to the right and is separated from the left wall of the chest by a comparatively thick layer of lung. (Vide infra). This position of the heart exercises considerable influence on the percussion

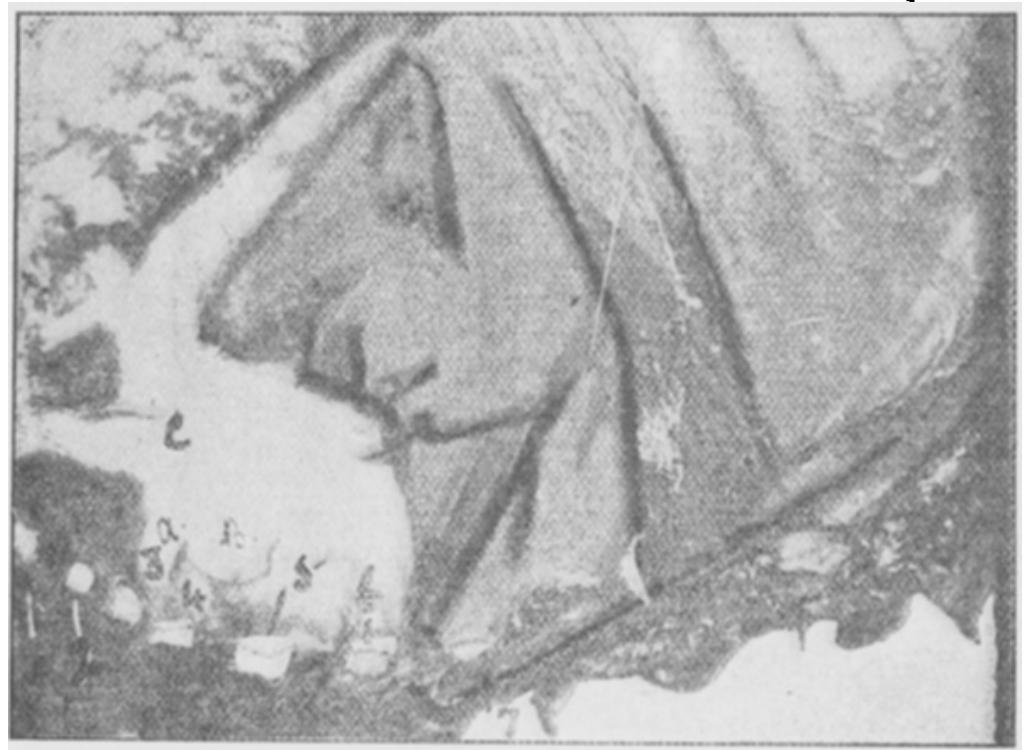

FIG. 2 ,

note of the region in question. The commencement of the pulmonary artery and the common aorta correspond to the 3 rd intercostal space and 4th rib. (Figs. I and 2.) The former lies below and to the left of the latter. (Figs. $2 a$ and $c$.) The heart, then, corresponds to the $3 \mathrm{rd}, 4$ th, 5 th, and 6 th ribs, the base of the left ventricle projecting into the 6 th space (between 6 th and 7 th). It is

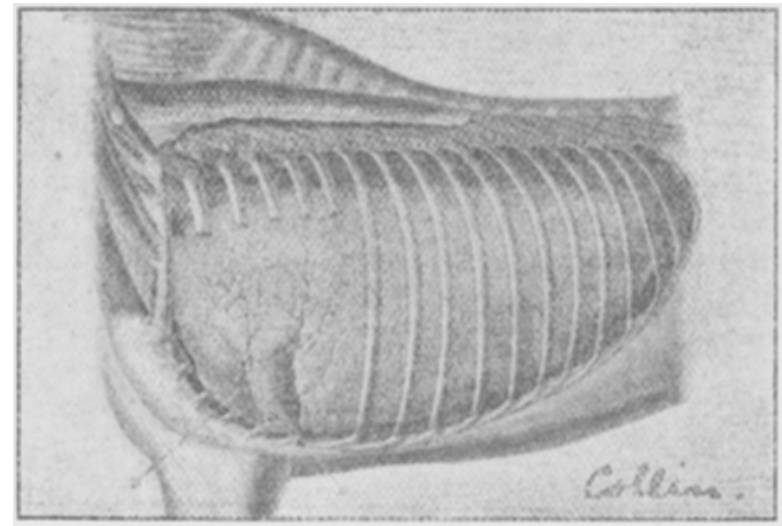

FIG. 8.

not at every point equi-distant from the chest-wall. It is separated from it by lung tissue except in an area corresponding to the $3 \mathrm{rd}$, 4 th, and 5 th intercostal spaces and extending upwards to about the left auricular appendix. 
In this region a furrow exists in the left lung, which allows the heart-wall to come into direct contact with that of the chest. (Fig. 3). The thickness of the intervening layer of lung varies at different points. It is greatest posterior to the 6 th rib and least at the borders of the furrow.

The superior part of the groove lies about $2 \frac{1}{2}$. inches above the anterior part of the 6th chondro-costal gomphosis, which also marks its posterior border. From the supro-posterior limit it slopes downwards and forwards to the 3 rd costal gomphosis. The extent of this furrow varies slightly in different individuals and with the respiratory movements.

The above description is taken from animals whose lungs were inflated after death until they filled the chest cavity.

Displacements of the heart are modified by its relations to the chestwall, the lungs, the great vessels, and the attachment of the pericardium to the floor of the thorax.

\section{PERCUSSION OF THE HEART.}

The observations on extension of the cardiac area here noted refer to the enlargement of the heart spoken of as hypertrophy. The area of cardiac dulness is also increased in hydrops pericardii, certain lung

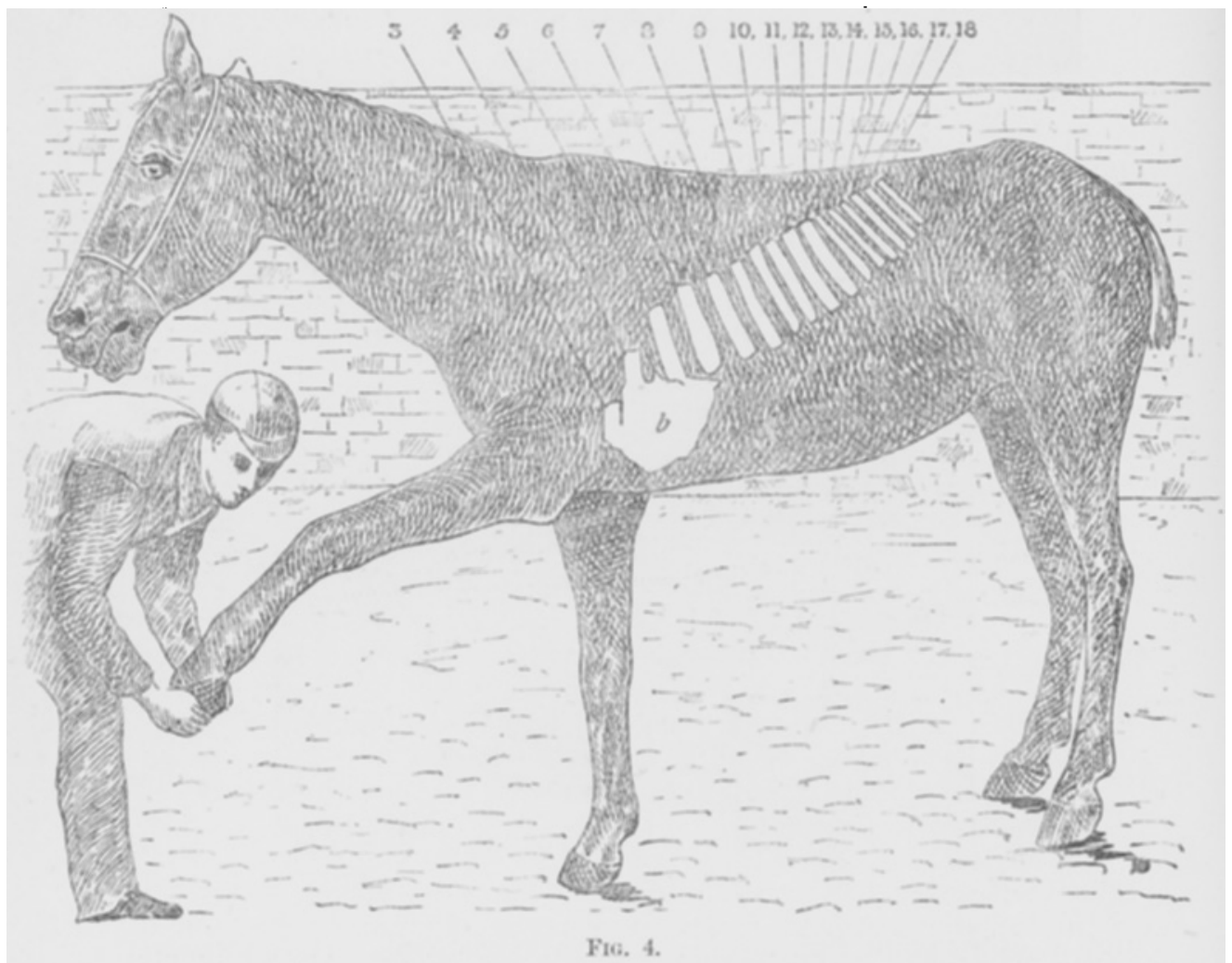

lesions and displacements, but of these I do not intend to speak. Without entering into the reason for it, it may be said, that the more 
deeply the solid organ is situated, the stronger must be the percussion to establish its presence.

In the living horse standing in the natural position the 3 rd and 4 th ribs, and the 5 th rib except at its lower third, are covered by the caput magnum and caput medium of the triceps extensor cubiti, which are inserted into the olecranon process. In this position a large part of the heart is inaccessible to physical examination, but, if the leg be pulled forward, the obstacle is removed. The most suitable position for examination I find to be as follows. Let the left foreleg be pulled forward by an assistant, until the lower part of the 3 rd rib is exposed. The limb can be held in this position without seriously inconveniencing

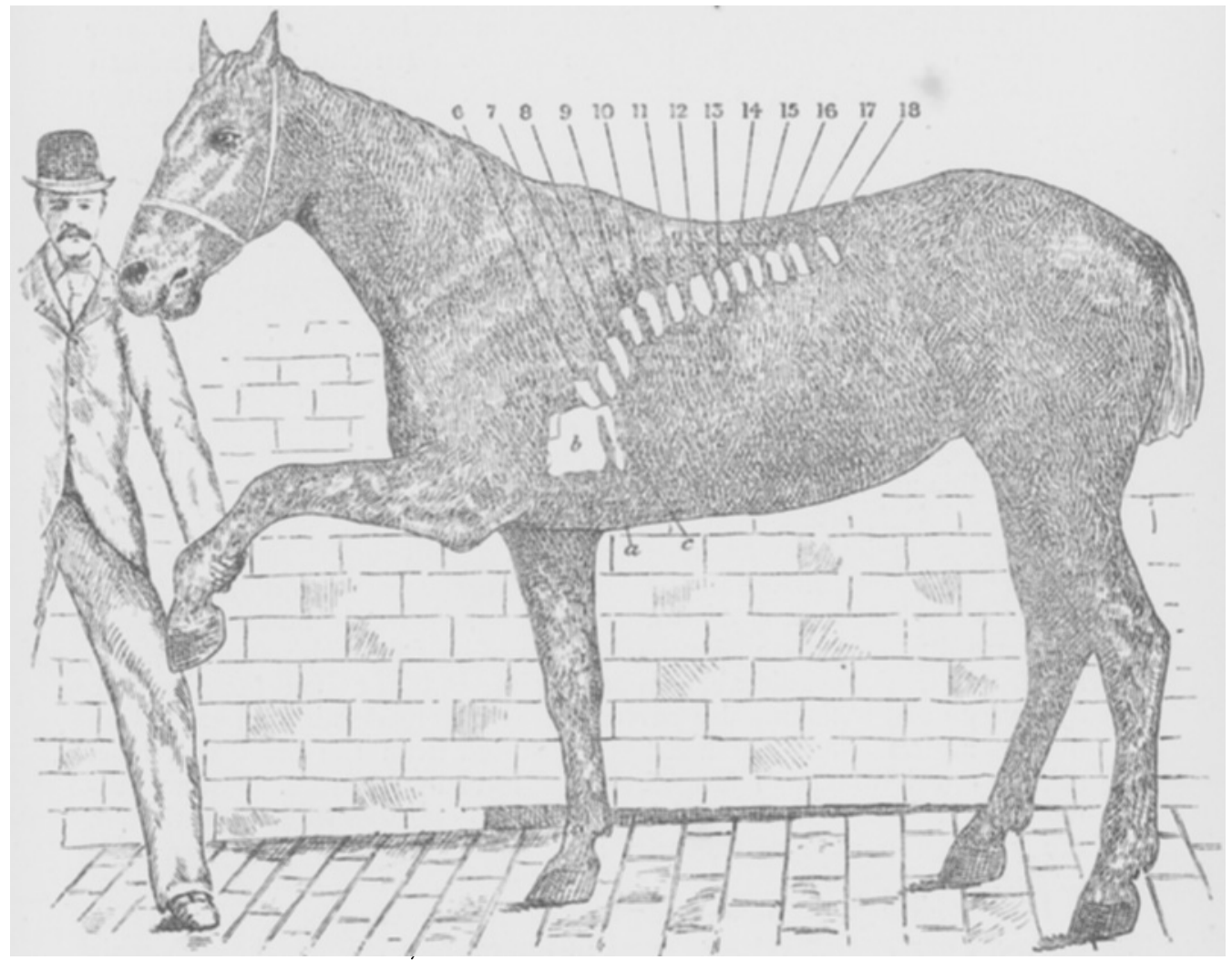

FIG. 5.

the patient. It is that in which all my examinations and markings have been made. (Figs. 4 and 5.) It has a second advantage of rendering tense the skin and muscles on the chest-wall, and so facilitating percussion.

One proceeds now to find the superior limit of the heart. An area corresponding to the $5^{\text {th }}$ intercostal space is chosen in the middle third of the chest-wall. One expects the percussion note to be freely pulmonal here. Percussing strongly the while, the pleximeter is moved gradually downwards, until the note lọses its decidedly clear character. 
The change in the percussion note is by no means an abrupt one, for the base of the heart lies some distance from the chest-wall and is covered by a comparatively thick layer of lung tissue. It must also be remembered that the auricle is by no means so solid a structure as the ventricle. In a few animals it is possible to delineate the base by percussing strongly, but in the majority it is almost impossible. This area may, of course, be important enough, when the auricle is hypertrophied.

The first really distinct indication of dulness is due to the presence of the left auricular appendix, which is partly covered by the 5 th rib. With a piece of chalk-contrasting the colour with that of the patient -a horizontal line is drawn through this point.

Below the line, thus drawn, the dulness is absolute (Figs. 4 and 5).

The line lies about io inches from the keel of the sternum and corresponds very nearly to the base of the ventricles. To establish the posterior limit of the heart one begins to percuss well back in the lower third of the chest-wall, moving forwards until the note changes. At the first indication of dulness a perpendicular line is drawn, so as to pass through the horizontal one. The space between these lines makes up the area of cardiac dulness (Figs. $4 b, 5 b c a$.)

The percussion note has not the same character in all parts of the cardiac area, as already pointed out with regard to the superior limit. Posteriorly deep dulness begins about the 6 th intercostal space; it does not become absolute until the $5^{\text {th }}$ rib is reached (Fig. 5, $b, c$ and $a$ ). I regard this area (a), extending from the posterior border of the 5 th rib into the 6 th space, as of the greatest importance in the diagnosis of hypertrophy of the left ventricle. When the dulness in this area $(a c)$ is absolute, one may conclude that the organ is enlarged. It is often stated, that a heart extending beyond the 7 th rib may be looked on as hypertrophied. So it might, but to extend so far back the thickness of the ventricular wall would have to be increased to the extent of over I inch. This would be an enormous hypertrophy. An extension backwards of half an inch would, indeed, signify a very considerable hypertrophy, but one can imagine the difficulty in establishing by percussion so inconsiderable an extension in this region, where the heart is separated from the chest-wall by a relatively thick layer of lung tissue. I have never found cardiac dulness beyond the 7 th rib, and have come to consider the alteration in the percussion note of the area marked $a$ in Fig. 5 of the greatest importance.

If one be well acquainted with the relative amount of dulness in different parts of the cardiac area in the normal animal, the diagnosis of hypertrophy becomes easy.

The feeling of resistance conveyed by the chest-wall to the finger is not without importance, especially in the intercostal spaces, which correspond to the cardiac furrow of the left lung. By palpation one may also discover fremitus, but this will be dealt with later.

\section{AUSCULTATION.}

Sounds of the Heart.-It is generally agreed that the first and second sounds of the heart are due mainly to closure of the auriculoventricular and semilunar valves respectfully.

Probably in the normal heart the mitral valve contributes most largely to the first, and the aortic semilunar to the second. Normally 
the auriculo-ventricular valves remain open until the pressure in the ventricle becomes greater than that in the auricle, when they close mechanically.

The closure of the auriculo-ventricular valves-first sound-is coincident with the commencement of systole. The semilunar flaps are forced against the arterial wall at the beginning of the ventricular contraction, and remain so, until the arterial pressure exceeds that in the ventricles. During systole the pressure in the arterial trunks rises, until by the emptying of the ventricle and the tension of the arterial wall it becomes greater than that in the ventricular cavities. At this stage the elastic recoil of the artery forces the contained fluid to seek exit forwards and backwards. The backward stream closes the uninjured semilunar valves, and fills the coronary arteries.

After closure of the semilunars the greater part of the recoil force is expended in driving the blood in a forward direction through the lungs to the left auricle in the case of the pulmonary artery, to the tissues in the case of the aorta. In the normal animal the ventricles contract synchronously, and the closure of the semilunars-second sound-pretty nearly marks the commencement of diastole. After the second sound comes a relatively long interval of silence. This interval covers the passive refilling of the cavities and the auricular contraction, which completes the diastole. The diastole completed, the systole commences, and the silence is terminated by the first sound.

The sounds of the heart are heard best in the areas which correspond most nearly to the seat of their production. The second is best heard at the anterior border of the 4 th rib in the cardiac area. Its distinctness decreases as the stethescope is moved backwards. It is carried well down the ventricular wall. The first sound is well heard at the anterior border of the 5 th rib. It is carried well backwards and downwards over the extent of the ventricular wall. It diminishes as the stethescope is moved forwards, till at the posterior border of the 3 rd rib it is almost gone. The above is what I have found to be the case in the majority of horses, but it cannot be called exact for all.

In patients whose hearts work intermittently the sounds are for the time suspended. Intermittency is sometimes present with valvular lesions, but there are other cases where no such lesion exists. The latter probably depend on some nervous disturbance. This form is frequently found in horses, and does not necessarily cause any inconvenience. One or other of the sounds may be double, when the auriculo-ventricular or arterial valves fail to close synchronously. The absence of synchronism depends on the pressure being abnormally high or low in one or other of the cavities. For example, a high pressure in the right auricle will retard the closure of the tricuspid, while a high pressure in the pulmonary artery will cause its valve to close sooner. These reduplications often occur in health, and are supposed to be connected with the changes in intrathoracic pressure dependent on respiration. In the horse the first sound is frequently double when no lesion exists.

This was first pointed out to me at the Clinique de l' école d'Alfort, where it is commonly met with. I have often come across it since, and have also met it in connection with broken wind and slight tricuspid incompetence. The sounds may be otherwise considerably 
altered, when valvular lesions are present. Sometimes one sound is replaced by a murmur. In mitral insufficiency the intensity of the first sound is much decreased, while the second sound may be intensified owing to the heightened pressure in the pulmonary artery. For the same reason one might expect reduplication of the second sound, but I have never met with it; neither have I come across a reduplication of the first as a result of aortic regurgitation. One would hardly expect it, seeing that the ventricles themselves in time become dilated.

\section{MURMURS.}

When a valve becomes incompetent, it allows the blood to pass backwards. By this stream meeting with the advancing one an eddy is produced and a murmur arises. When one of the orifices is constricted, the volume of blood passes through it with greater difficulty into a relatively wide cavity beyond; a murmur results. With regard to the raison ditre of murmurs under these conditions, I wish to say as little as possible. The question is a vexed one.

The observation of Savart on the production of a sonorous liquid vein is held by many authorities to be the explanation of murmurs occurring at the cardiac orifices. In connection with each orifice two different murmurs are possible, one due to insufficiency of the valves and another due to constriction of the passage. In speaking of the time at which murmurs occur it is usual to identify it with that of systole or diastole. They are spoken of as systolic and diastolic. During systole, then, two murmurs may arise, one due to incompetence of the auriculo-ventricular valves and another due to constriction of the arterial orifice. Similarly, two are possible during diastole, one due to incompetence of the semilunars and a second arising from constriction of the auriculo-ventricular orifice. Two forms of the latter are recognised. The one spoken of as diastolic begins shortly after the second sound and is continued nearly up to the first.

The latter part of it, which corresponds to the auricular contraction, is more intense. The other form, which only arises with the auricular contraction, is spoken of as præsystolic.

To be able to say whether a murmur is due to stenosis or incompetence, whether it arises at the orifices of the left or right heart-for both sides contract synchronously-attention must be paid to the following points :-

I. The time of the murmur (systolic or diastolic).

2. The character of its sound.

3. The region where it is best heard.

4. The area over which it is conducted.

5. The amount of pulsation seen in the large veins and the character of the arterial pulse.

Time.-In order to find with what part of the cardiac revolution a murmur is coincident, one places the finger on the area of impulse or on an artery as near as possible to the heart.

In the horse there is little difference between the time of the pulse wave at the post-radial artery and that at the carotid, where it is available to the finger. The former artery is the more convenient of the two. When the existence of a murmur has been established, the left leg is allowed to come backwards until the post-radial pulse can be conveniently felt. 
The pulse wave being coincident with the commencement of systoleclosure of auriculo-ventriculars-murmurs starting with the pulse will be systolic in time. Those heard after the pulse or better after the second sound will be diastolic. The sounds themselves furnish a good guide. The first, however, may be completely replaced by a murmur ; the second is seldom absent.

Character.-In the human patient murmurs of stenosis are generally described as being harsh in character, while those of regurgitation are said to be soft or bellows-like-bruit de souffle. Speaking of the horse, it would be wrong to say that regurgitant murmurs are invariably soft in character, unless they be so relatively to those of stenosis. As I have had almost no experience of stenosis murmurs, however, I can say little about them.

During regurgitation the forcible passage backwards of a large volume of blood seems to give the murmur a more or less harsh character, and it must not be forgotten that during systole the auriculoventricular orifice is relatively constricted, unless the ventricle be much dilated, but they are not always harsh. It may be that the harshness of a systolic murmur at the auriculo-ventriculars is inversely related to the amount of dilatation, but my post-mortem examinations are too few to allow the assertion. As regards the aortic orifice, I have not as yet met with a regurgitant murmur that was not decidedly harsh. I had the opportunity of auscultating a horse with a harsh aortic diastolic murmur, while the animal was being killed for the dissecting room - the animals are killed by bleeding - and I found that the harshness diminished with the pressure, until the sound came to resemble a bruit de souffle. This animal showed no signs of early fainting, nor did death take place more quickly than in horses with sound hearts. The commonest murmur which claims to be called soft is probably the tricuspid systolic.

Some murmurs are distinctly musical in character. I have met with four such, one of which could be heard a little distance from the chest-wall without the aid of the stethescope. All of them arose at the aorta and were diastolic in time. The sound resembled the cooing of a dove. The musical character seems in most cases to be due to vibration of a detached piece of cusp. At the postmorten examination of one case I found a piece of membrane about the thickness of thin twine detached from the body of a cusp along its free margin. The membranous thread was adherent at both extremities.

I have not seen any record of anæmic cardiac murmurs in veterinary patients. They are common enough in human patients. In connection with their production, the following observation may be of interest. If in the dead heart of a dog the pulmonary valves be destroyed and the vessel connected with a tube through which passes a stream of water at a certain pressure, it will be observed that the tricuspid flaps float upwards with the filling of the ventricle, but that they still allow the fluid to come through into the auricle. If the pressure be raised, however, the cusps overlap at their points and margins, putting an end to regurgitation. I do not know, however that the pressure in either ventricle is abnormally low in anæmic patients. The so-called "bruit de diable" can, I think, have little diăgnostic value in the horse, because in the normal animal the 
slightest pressure with the stethescope on the jugular vein gives rise to a sound like the distant hum of a threshing machine.

Area where best heard.-The points of maximum intensity of murmurs arising at the several orifices have been accurately enough defined in man. I have endeavoured to do so in those cases with which I have met in the horse. They will be described in connection with each lesion. As a general rule, however, it may be said that murmurs are best heard at the part corresponding to the seat of their production, if the latter be in close proximity to the chest-wall. If the seat of production be some distance off-tricuspid-the sound is conveyed to the chest-wall through the intervention of some solid body, such as the ventricular muscle. In the latter case it is best heard where the conducting body contacts with the wall of the chest. (See tricuspid systolic.)

Areas of Conduction.-It is stated as a general rule that cardiac murmurs are conducted by the solid tissues in the direction of the blood-stream which gives rise to them. From observations on the horse it seems to me that the direction of the blood-stream is a secondary factor. I have heard a musical aortic diastolic murmur which was propagated half-way up the carotids, although, it was also carried towards the apex.

The mitral systolic is sometimes well heard near the apex, being carried down by the ventricular wall. I have never yet come across a tricuspid systolic that could be heard over the jugulars at the root of the neck. The area of propagation seems to depend more on the loudness of the murmur and the amount of cardiac hypertrophy. The latter factor, of course, comes under the head of solid tissues available for conduction.

\section{THE ARTERIAL PULSE.}

The character of the arterial pulse is considerably altered by lesions of the left heart. Some of these changes can be established by placing the finger on the artery, others require the use of special instrumentssphygmographs of Marey or Dudgeon-for their identification. To the physician the latter method furnishes a valuable aid to diagnosis and prognosis. Changes in rhythm and volume are, of course, appreciable by the finger I have as yet made little use of the sphygmograph, except as regards the pulse of aortic regurgitation. I intend to continue my observations as cases present themselves. The tracing H, Fig. 8, was taken by means of a Dudgeon's sphygmograph from the maxillo-muscular artery of a horse which presented an aortic diastolic nnurmur, due to rupture of one cusp. If it be compared with a normal pulse tracing ( $G$, Fig. 8) the following differences are notable. The line of descent $b-g$ instead of bcing gradual is abrupt. Further, the wave $c$ in the descending line, which in the normal pulse is a wave arising from the closure of the aortic valves-dicrotic wave-is absent or nearly so in the tracing of aortic incompetence. This is the "water hammer pulse," also known as Corrigan's pulse. Its character can be partly translated by placing the finger on the submaxillary artery. At each systole a large volume of blood is driven into an abnormally empty aorta, producing a sudden and full distension. Thus, a very forcible pulse-wave is sent along the relaxed arteries and can be felt at the superficial ones. As the 
blood regurgitates through the incompetent valves, the wave is felt to subside quickly. The regurgitation accounts for the abrupt line of descent $b-g$ in tracing $\mathrm{H}$.

\section{VENOUS PULSE. (Figs. 8-I2.)}

In the normal horse distinct pulsations are seen in the jugular veins at the root of the neck. These pulsations do not extend any distance up the neck. They correspond in number to the heart beats and do not depend wholly on the respiratory movements, although with violent exertion-embarrassed respiration-they may become more evident. This exaggerated venous pulse (which probably originates in congestion of the pulmonary vessels), may be well seen in horses cast for operation. Speaking with regard to the horse, we may call the first form the normal venous pulse. In the jugulars it is certainly mixed up with the carotid pulsations. As I am not yet sure of its significance, I leave this to a future paper. That it is not due to a natural incompetence of the tricuspid, I have convinced myself, for the valve is competent in the normal horse. I have also assured myself that the jugular valves, if competent under ordinary pressure, become incompetent on the slightest dilatation of the vein. This can be demonstrated by excising the vein and allowing a stream of water to pass along it from the cardiac end. No matter how small the stream may be it passes along without interruption. When acquainted with the average volume and extension of this pulsation, one readily recognises an abnormal increase.

The latter is a valuable aid to the diagnosis of heart affections and helps one to differentiate between murmurs at the right and left orifices. A murmur at the mitral is likely to be accompanied by a smaller increase than one at the tricuspid.

The venous pulse in the human patient is the subject of a recent and very exhaustive paper by Dr J. Mackenzie, Burnley. The paper will be found in the Journal of Pathology and Bacteriology, vol. ii., Nos. I and 3. As an introduction to a future paper on the venous pulse of the horse, I should like to give here some extracts from Dr Mackenzie's paper. I am much indebted to Dr Mackenzie for his kindness in allowing me to do so, and for permission to use his tracings for this article. For my observations, as yet few, on the venous pulse of the horse, I have employed the phlebograph described by him. I shall not at present enter into a description of it; suffice it to say, that the instrument referred to registers pulsations by air-waves transmitted to a tambour. In the above-mentioned paper the different events in the venous pulse have been timed by comparing them with those of an arterial tracing from an artery about the same distance from the heart as the vein under observation. It is assumed that a venous wave in the jugulars travels from the heart at the same rate as an arterial wave in the carotid. The apex beat is also taken as a standard of time, due allowance being made for the lapse of time between it and the pulse-wave in the arteries.

In the venous pulse of moderate dilatation there are two distinct waves, Fig. 9. The one, $a$, corresponds in time to the ventricular systole. It appears towards its end after closure of the semilunar valves. It will, therefore, be evident in the jugulars at a later period 
than the pulse in the carotid. (Compare venous tracing with arterial in Fig. 9.)

The ware $a$ is followed by a large wave $b$, due to the auricular contraction. The latter wave is succeeded by a well-marked depression $x$, arising from the filling of the auricle and the first part of the ventricular diastole. In most of Mackenzie's tracings from the jugular, the auricular depression is interrupted by a third wave $c$, Fig. IO. He has taken great pains to show that $c$ is the pulse-wave communicated from the carotid to the overlying jugular.

He shows that $c$ occurs at the same time as the carotid pulse (compare carotid and venous tracings, Fig. IO), and that it is absent from tracing of the liver pulsations. Its presence in this part of the tracing seems hard to understand at first, but if it be remembered that the arterial pulse arises at the start of systole, while the ventricular wave $a$ of the venous pulse arises at its close, it will be readily seen how the systole, causing $a$, can also be the cause of the wave $c$ anterior to it.

From one of my few observations I can supply additional proof of $c$ being arterial in origin. The tracing $\mathrm{D}$, Fig. 8 was taken from the jugular of a horse affected with aortic insufficiency.

In the lower part of the neck the jugular vein and carotid artery lie in direct contact, the former being external to the latter.

In aortic incompetence one expects a large pulse-wave. In this case I was struck with the large size of the venous pulse in connection with a lesion of the left side, but on taking the pulse at the post-radial I found that the large wave seen in the jugular furrow corresponded in time to the arterial pulse.

When the vein was temporarily obliterated by pressure, this pulsation continued above the seat of obliteration. The post-mortem examination revealed secondary dilatation of both ventricles. For lack of necessary assistance I was unable to obtain a pulse tracing at the same time, but took one immediately afterwards on a cylinder revolving at the same rate, Fig. $8 \mathrm{~F}$. I find that the arterial waves in Fig. F are separated from each other by the same distance as the large waves $c$ in Tracing $D$.

Speaking with regard to human patients, Mackenzie says that pulsation in the veins can only be seen when the right heart is abnormally distended, Under this condition the mouths of the consequently engorged veins do not close as completely as in health. A certain amount of blood, therefore, is forced into the veins at each auricular contraction, giving rise to a positive wave. The ventricular wave has a similar explanation-the ventricular systole-when the tricuspid is incompetent.

A tracing is not necessary to demonstrate the double wave of the venous pulse in the horse. One can observe it with the unaided senses.

By timing his venous tracings with the pulse and apex beat, it seems that the latter wave appears at the close of systole, Fig. I I.

The reason given for the ventricular wave appearing at this time in the tracing will be found in the following explanation of the venous pulse.

The auricle and venæ cavæ are practically one cavity, variations of pressure in the former being reflected in the latter. That is to say, a 
fall in the auricular pressure will cause a negative wave in the veins, as a rise will produce a positive one.

Further, when the tricuspid valve is open or incompetent, the right ventricle will also be in communication with the veins through the auricle, and variations of pressure in the ventricle will also be reflected in the veins. Agreeing with those who think that the right ventricle never completely empties itself into the pulmonary artery, the pressure in that vessel becoming great enough to close the semilunar valves before the end of systole, Mackenzie suggests that the remainder of the systolic force will be wholly expended in driving the residual blood backwards into the auricle, which at the close of systole is pretty full and in direct communication with the venous contents through its own; hence, the ventricular wave of the venous pulse appears in the tracing at a latter period than the arterial wave $c$. His tracings further show that in the ventricular form of the venous pulse (vide infra) the greatest rise takes place after closure of the semilunar valves, Fig. I2.

Two principal modifications of the venous pulse are shown by tracings. Firstly, one in which the auricular wave $b$, Fig. 9, is separated from the ventricular $a$ by a well-marked depression $y$, due to the auricular diastole, while the closure of the tricuspid is still partially effective. Secondly, a form in which the ventricular wave is the most marked feature, the auricular being absent or nearly so. The latter is called the ventricular venous pulse by Mackenzie, who explains it as follows :-

With increasing tricuspid incompetence the auricle becomes more and more dilated and enfeebled, until, practically paralysed, it ceases to originate movements in the veins, but merely reflects passively those movements originating in the ventricle. The venous pulse, then, of advanced dilatation shows only one fall due to the diastole of the ventricle and one rise due to its systole. In less advanced cases the auricular contraction is still represented. By tracings, which I have been unable to obtain, Mackenzie further demonstrates the evergrowing ventricular wave at the expense of the auricular. The tracings were taken from seven patients with different degrees of dilatation, but with advancing incompetence one might expect to see the several modifications in the same patient at different stages.

\section{TRICUSPII INCOMPETENCE. (Fig. 6.)}

Although, according to all post-mortem evidence, the right side of the heart is seldom the seat of anatomical lesions, it is in connection with the tricuspid valve that I have most frequently observed murmurs. I have no hesitation in saying that the right auriculo-ventricular orifice is most frequently the seat of a murmur in the horse. The right ventricle often becomes dilated, and tricuspid incompetence results. This dilatation may be secondary to emphysema of the lungs, but it frequently occurs without it. I have met with it most commonly in that class of animal which is subjected to fast and heavy work. Thus it may be repeatedly met with in tramcar and 'bus horses.

In Edinburgh, where the streets are hilly, I find a large percentage of the above class of horses affected with dilatation of the right ventricle. Out of twelve 'bus horses examined by me in one stable, eight were found to have tricuspid incompetence. 
It is not to be wondered at, when one thinks of the severe strain put upon the heart and respiratory organs by such work. The drivers of these animals often pronounce them to be touched in the wind, because they blow hard when pulling uphill, but a large number of them show no symptoms of broken wind other than dyspnœa. The cough, if present, is not characteristic, nor do the respiratory movements resemble those of emphysema. This dilatation may take place

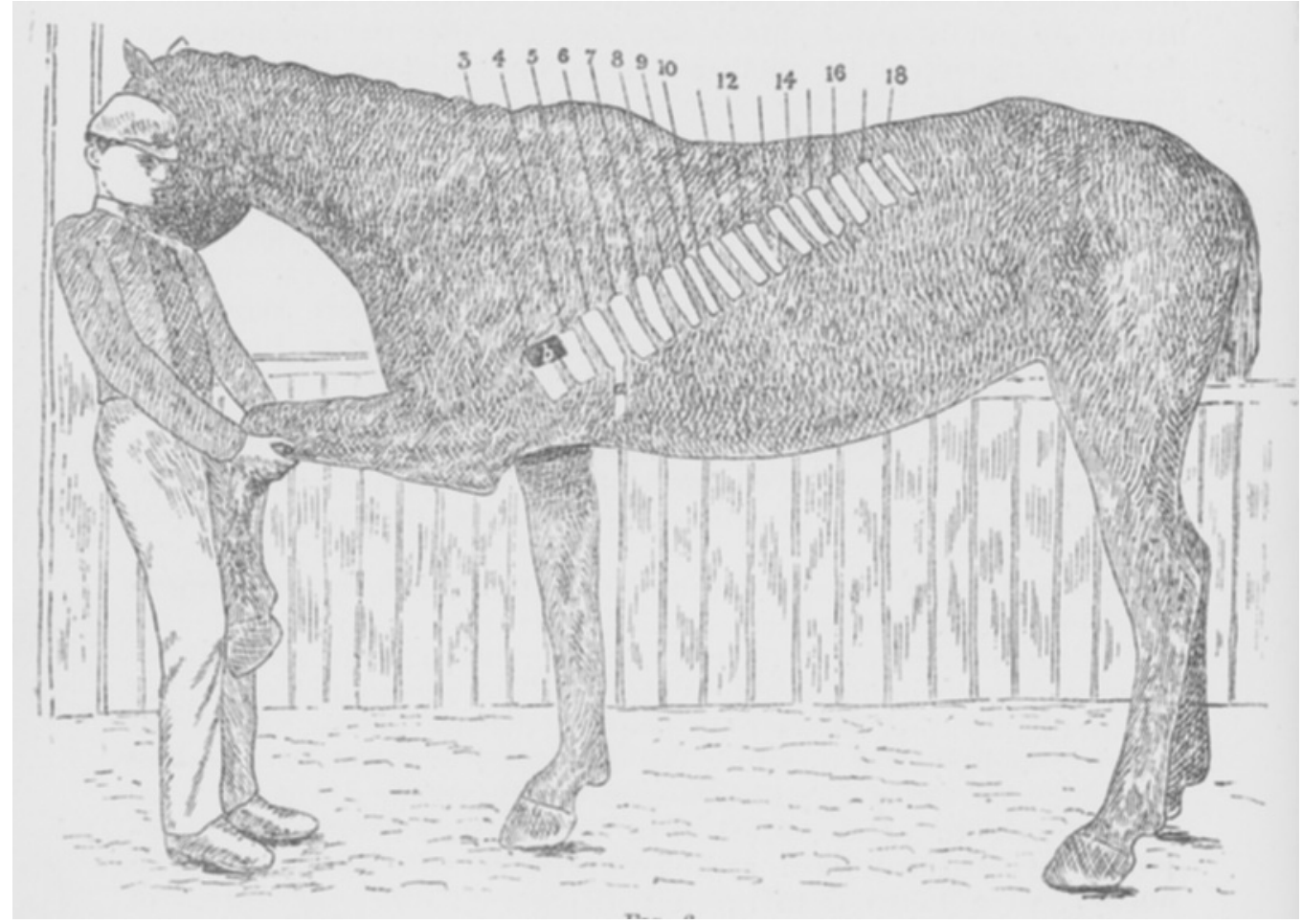

FIG. 6.

in a comparatively short time. I have seen the murmur arise in a horse hitherto sound, after three weeks of 'bus work in a very hilly part of Edinburgh. The attendant told me that the horse had formerly worked well, but had become touched in the wind since being put to pull the 'bus.

The murmur may disappear after rest and treatment, but it is liable to recur, and such an animal could not be looked on as sound.

Not a few of the animals in which this murmur is present are said by the drivers to work well.

The A Mumum:-On pulling the left leg well forward, a systolic, murmur, coincident with the pulse, is heard at the posterior border of the $3 \mathrm{rd} \mathrm{rib}$, about $8 \frac{1}{2} \cdot$ inches from the keel of the sternum, in the groove formed between the caput magnum and the chest-wall (Fig. 6). Its area of conduction is very limited. It is carried no more than I $\frac{1}{2}$. inches backwards along the base of the heart, and about the same distance downwards in a slightly backward direction. It is probably carried to the above-mentioned region by the anterior part 
of the right ventricle, which corresponds to this area on the left side of the chest.

The distinctness, with which it is heard here, may also be due to the feebleness of the first sound itself at the level of the $3 \mathrm{rd} \mathrm{rib.} \mathrm{At} \mathrm{this}$ part the murmur seems to replace the first sound, whereas at the 5 th rib the sound is distinct enough, while the murmur is absent. The souffle is by no means a loud one, nor is it harsh. For that reason, and from the difficulty attending the exploration of this region, the use of the stethescope is almost necessary to obtain a good idea of it. It is not carried to the apex, which is formed by the left ventricle. On percussion no backward extension of the cardiac area is perceptible, nor would one expect it, seeing that the posterior border of the organ is formed by the left heart.

The venous pulse is usually well marked in the jugular veins in comparison to the intensity of the souffe. A systolic mitral murmur of the same intensity would be accompanied by less regurgitation into the veins, unless secondary dilatation of the right heart were present.

Of the other murmurs occurring at the right orifices I have had no experience. From all records the pulmonary orifice in the horse is seldom the seat of lesions. I have read of only one case of tricuspid stenosis, The latter lesion would give rise to a harsh murmur, diastolic or prasystolic in time, that is to say, it would be heard before the first sound or the pulse. At the pulmonary artery two murmurs are possible, a systolic bruit of stenosis, and a diastolic souffle of incompetence.

\section{MITRAL STENOSIS.}

I have as yet met with only one case of mitral stenosis. The patient was a pony aged seven years. As the said animal was working in a coal mine my observations on the case are incomplete. The pony was in poor condition; did not eat well ; suffered from dyspnœa at work; pulse weak and irregular. The heart palpitated irregularly when the animal was submitted to examination. The venous pulse was little marked. A feeble præsystolic murmur was heard over a limited area.

\section{MITRAL INCOMPETENCE.}

My experience of this lesion has been mainly in connection with aortic insufficiency, of which it is almost a constant accompaniment.

I have met with one or two cases of independent mitral incompetence, but have never had the opportunity of photographing the areas. The lesion gives rise to a systolic souffle which is coincident with the pulse and may almost completely replace the first sound. It is continued up to the second sound, which closes it. It is well heard about the level of the 5 th rib and may be carried backwards to the 7 th. (The area of propagation varies with the amount of enlargement.) It is also carried well down towards the apex by the ventricular wall, and upwards by the dilated auricle. The second sound is often increased in loudness and may be double. To percussion the area of cardiac dulness is not much increased, unless there be great dilatation of the left ventricle. It is the auricle that undergoes hypertrophy. The venous pulse is not marked until secondary dilatation of the right ventrical has taken place. 


\section{AORTIC STENOSIS.}

Only two cases of this lesion have come under my notice. I saw both cases about three years ago, before I had planned this article. My notes of both cases are incomplete. A systolic murmur was present at the base. It was carried fairly well along the region of the chest corresponding to the aorta. The second sound seemed to be delayed.

The pulse was weak and irregular. In one patient vibration could be felt when the cardiac region was palpated. One of the cases was complicated with insufficiency of the mitral valve. In the other a systolic-diastolic murmur was present. In neither case was the venous pulse marked.

\section{AORTIC INCOMPETENCE. (Fig. 7.)}

I have met with this condition most commonly in well-bred horses of uncertain age. It appears to be fairly common, but I have postmortem notes of only two cases. One of these showed rupture of a semilunar cusp parallel to its free border. In the other (subject of

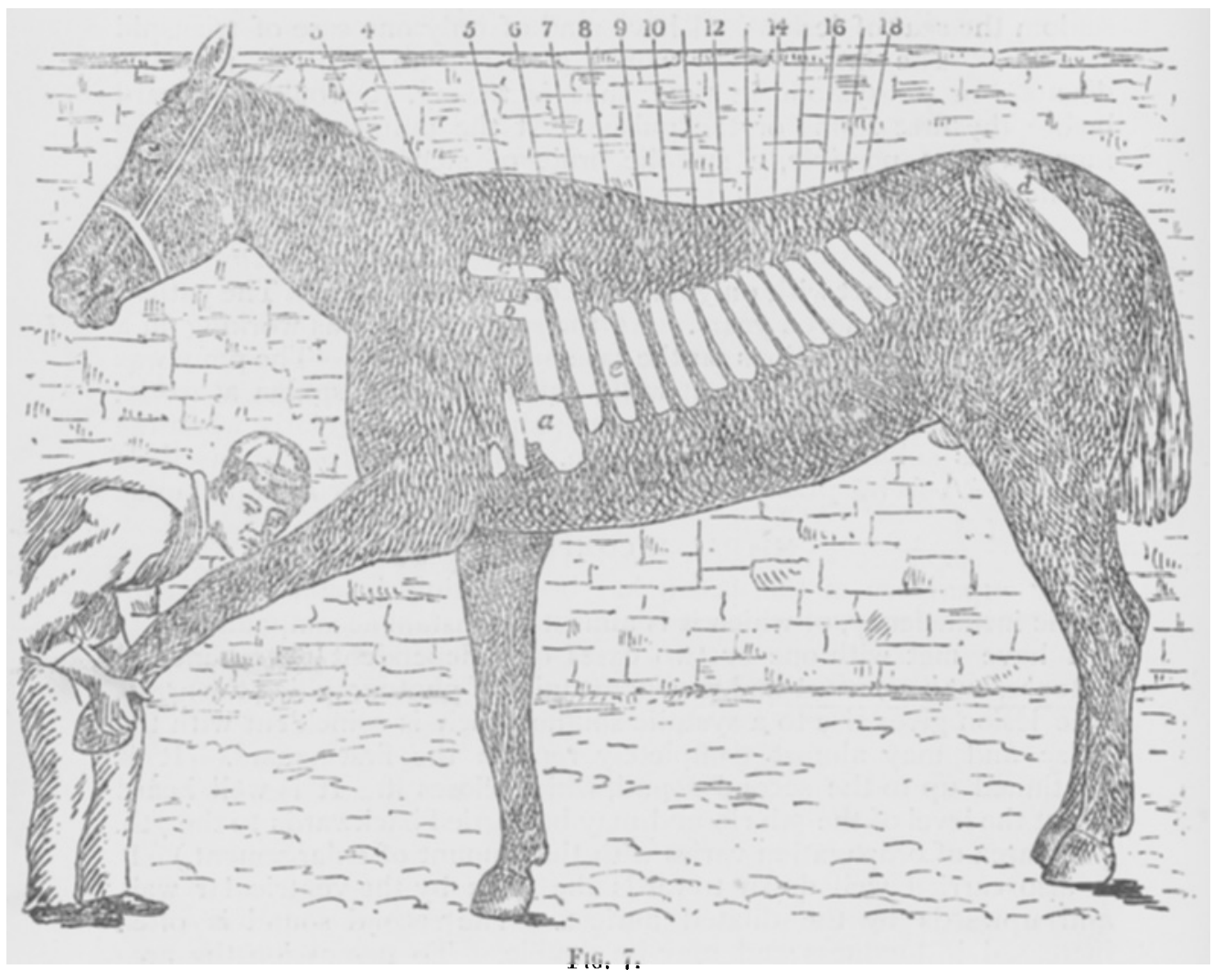

Fig. 7) calcareous patches were found, one of which included the base of a cusp where it joins the vessel wall. In each case secondary dilatation of both ventricles had taken place. 
The Murmur.-Aortic incompetence gives rise to a loud diastolic murmur immediately following the pulse at the radial. In the horse

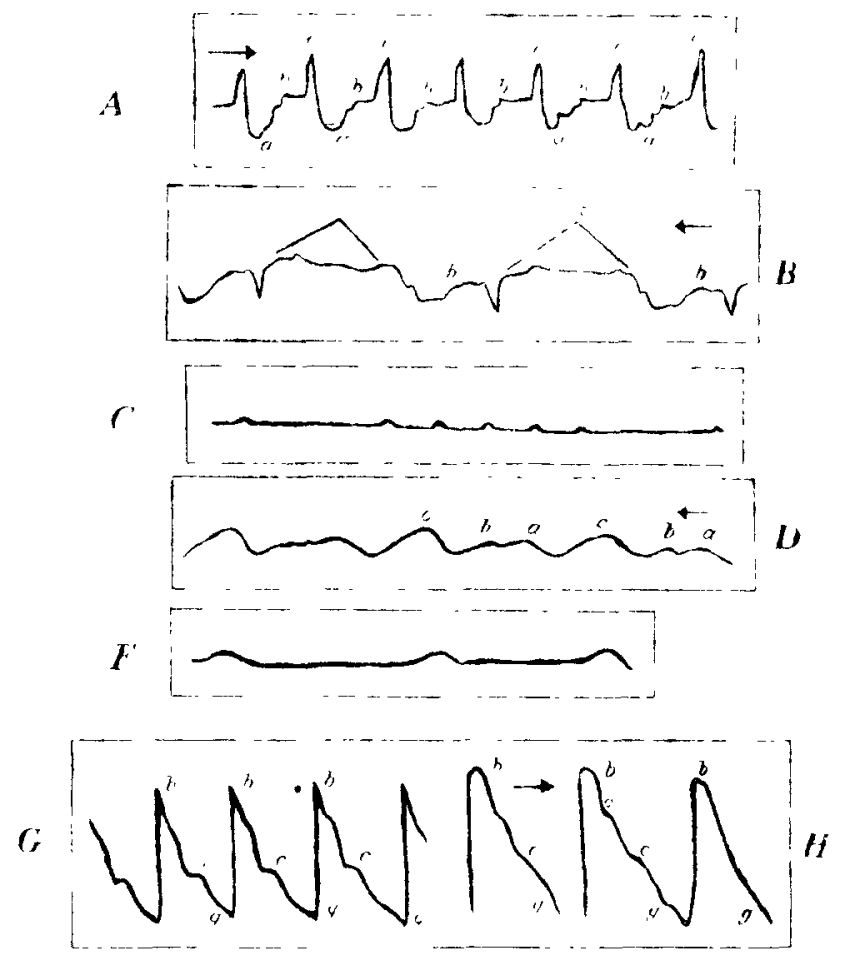

Fig. 8.

it is frequently musical in character and may continue right up to the first sound. The second sound may be completely masked by it. Sometimes the sound is heard towards the close of the murmur, and I

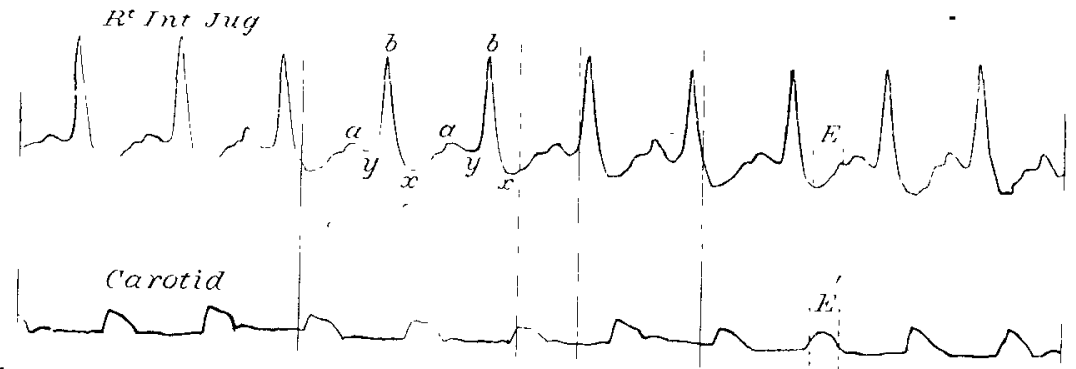

FIg. 9.

have thought it is possible that where the insufficiency of the cusps is slight and dependent on lesions near its free borders, they may again 
become competent with the recoil of the over-distended aorta. The murmur is best heard near the anterior border of the $4^{\text {th }}$ rib, about 8 t.

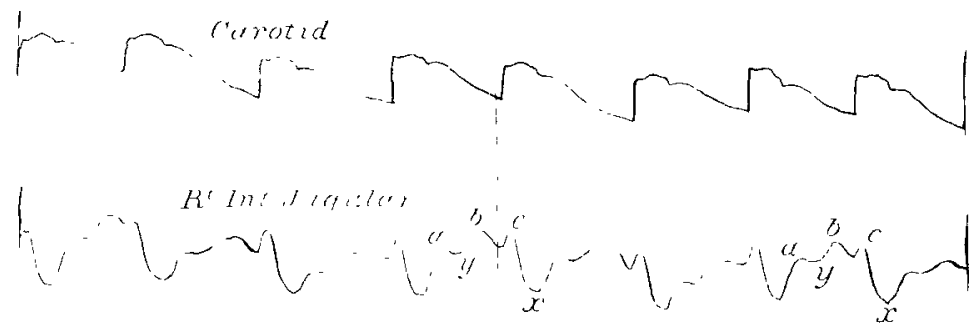

FIG, 10.

inches from the keel of the sternum (a, Fig. 7). At the base it is carried well backwards by the hypertrophied ventricle. In one of my cases where the murmur was loud and the hypertrophy extensive (post-mortem made) it could be heard at the 8th rib in a line with the base of the ventricle. It is carried well downwardsabout 4 inches-towards the apex in the area comprised between the posterior border of the $4^{\text {th }}$ rib and the anterior border of the 6th (4th and 5 th spaces, Fig. $7, a$ ). Although contrary to the direction of the stream causing the murmur, it may, when loud, be propagated well forward over the shoulder. I have heard it one-fourth way up the carotids, and upwards on the line of the $4^{\text {th }}$ rib (posterior aorta) to within $\mathrm{I} \frac{1}{2} \cdot$ inches of a horizontal line drawn from the tubercle of the scapula, as the subject of Fig. 7 can testify. (Vide $c$ the tubercle of scapula and $b$ the upward limit of the murmur.)

Percussion. - The area of absolute cardiac dulness is always markedly increased. It may extend backwards to the 7 th rib (Fig. $7 e$ ), at which point the murmur was also distinctly heard. The pulse in this disease is typical, although its character cannot

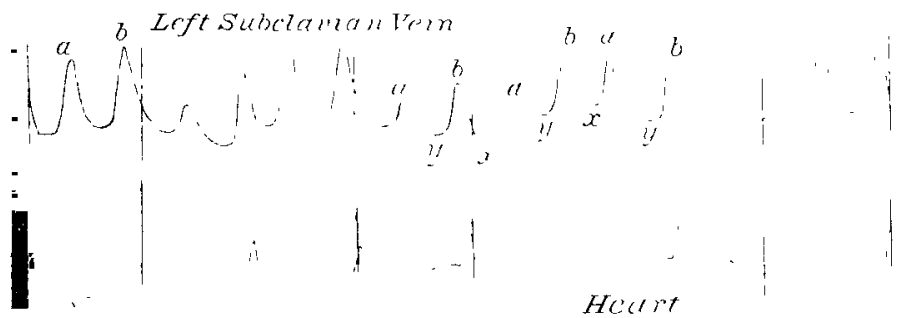

FIG. 11.

always be appreciated by the finger. It is the water-hammer pulse, the pulse of Corrigan. (See Tracing H, Fig. 8, which was taken from the subject of Fig. 7.)

In this same patient many of the superficial arteries could be seen to pulsate (superficial temporal, maxillo-muscular, transverse facial, muscular branch to the middle gluteus, etc.). This marked pulsation 
is explained by the large volume of blood thrown into the aorta at each systole.

The venous pulse is not marked in cases uncomplicated by dilatation of the right heart, but the carotid artery bounding beneath the

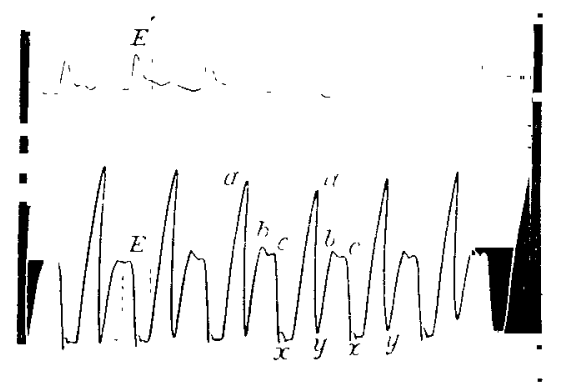

FIG. 12.

jugular vein may give rise to a very marked pulsation in the jugular furrow. On closer examination, however, it is found to be synchronous with the radial pulse, and to bound strongly under the finger. If the vein be compressed by the finger the pulsation still goes on above the point of pressure.

In concluding this paper I wish to express my thanks to Professor M'Kendrick, Dr James, and Dr Milne Murray for the loan of instruments and for instructing me in their use.

\section{DESCRIPTION OF FIGURES.}

FIG. I. Dissection showing the relation of the heart to the ribs; heart injected. Ribs are numbered from I-I2 above and from I-8 below. Heart extends from $3^{\text {rd rib to } 6 \text { th }}$ space. Common aorta corresponds to $4^{\text {th }}$ rib.

Fig. 2. The heart in relation to the ribs; heart injected. Heart extends from 3 rd rib to 6 th space; $a$, pulmonary artery; $c$, common aorta; $b$, left auricular appendix.

FIG. 3. Diagram of horse's chest, lungs inflated (Colin). Cardiac furrow in left lung from 3 rd to ant. of 6 th rib.

FIG. 4. Area of cardiac dulness, normal horse.

FIG. 5. Area of cardiac dulness, normal horse ; $b$, absolute dulness ; $a, c$, area of deep dulness extending from post. of $5^{\text {th }}$ rib to 6 th space.

FIG. 6. Tricuspid incompetence (slight). a, post. limit of absolute cardiac dulness (5th rib) ; $b$, seat of murmur and area of conduction.

FIG. 7. Aortic incompetence. $a$, seat of murmur (4th rib) and area of conduction downwards; $b$, upward limit of murmur; $c$, line drawn from tubercle of scapula; $e$, posterior extension of the base of left ventricle, (murmur well heard at $e$ ); $d$, seat of visible pulsating artery.

FIG. 8. $A$, cardiogram from normal horse (Knoll's cardiograph). $a, b$, auricular contraction; $c$, ventricular contraction.

$B$. Cardiogram from horse with hypertrophy of left ventricle (Knoll's instrument). $\quad c$, long maintained ventricular wave.

C. Cardiogram from horse showing intermission of one revolution after every five beats. 
$D$. Tracing from jugular of horse taken by Mackenzie's method after shaving the skin. $a$, ventricular wave; $b$, auricular ; $c$, carotid wave.

$F$. Arterial tracing taken on cylinder moving at same rate as in case of $D$.

$G$. Normal sphygmographic tracing from man, showing well-marked dicrotic wave $c$.

$H$. Sphygmographic tracing from maxillo-muscular artery of horse with aortic incompetence; $c$, almost gone.

FIG. 9. Tracing of venous pulse taken synchronously with the carotid pulse; $a$, ventricular wave; $b$, auricular wave ; $x$, auricular depression ; $y$, ventricular depression; $E$ and $E^{\prime}$, duration of outflow through the arterial orifices of the heart (Mackenzie, Journal of Pathol. and Bacteriol.).

FIG. Io. Tracings of carotid and jugular pulses taken at the same time; $a$, ventricular wave; $b$, auricular wave ; $c$, arterial wave, $x$, auricular depression (Mackenzie).

FIG. I I. Simultaneous tracings taken from the left subclavian vein and cardiac impulse. The sharp elevations in the lower tracing indicate the beginning of the ventricular systole; $a$, ventricular wave; $b$, auricular wave; $x$, auricular depression; $y$, ventricular depression (Mackenzie).

FIG. 12. Tracings of the radial pulse and of the pulse in the right internal jugular vein, to show the high ventricular wave $a$ after cessation of the ventricular outflow through the arterial orifice $E$.

\section{EDITORIAL ARTICLES. \\ IMMUNITY.}

IT is doubtful whether any subject in the whole sphere of pathology is more fascinating that that of immunity. It may with equal safety be said that no pathological point is more puzzling, for, notwithstanding the great amount of discussion and experimentation devoted to it during the last twenty years, some points in connection with what has been called the "mechanism of immunity" are still far from clear.

The main facts connected with immunity have been known from time immemorial. The horse does not contract the bovine disease called contagious pleuro-pneumonia, and the ox has a like freedom from glanders. There are examples of what is termed inherited or natural immunity. A man who has just recovered from an attack of small-pox will not contract the disease a second time, just as a dog that has had one attack of distemper is not liable to a second attack. This freedom from risk of infection which is conferred by a first attack of disease is termed acquired immunity.

Before endeavouring to discover what happens when the germs of an infectious disease find their way into the body of an animal that has acquired immunity by a previous attack, it is well to have clear notions regarding the way in which the germs of infectious disease produce their deleterious effects. The pathogenic bacteria are vege- 